\title{
Priority areas for jaguar Panthera onca conservation in the Cerrado
}

\author{
Marina Peres Portugal, Ronaldo Gonçalves Morato \\ Katia Maria Paschoaletto Micchi de Barros Ferraz \\ Flávio Henrique Guimarães Rodrigues and Claudia Maria Jacobi
}

\begin{abstract}
The jaguar Panthera onca, a threatened species in Brazil, is losing suitable habitat as a result of agricultural expansion and other forms of land conversion, especially in the Cerrado biome. In the current context of habitat loss and fragmentation, a network of protected areas is paramount for the conservation of this species. We aimed to identify jaguar conservation units in the Cerrado, and propose a ranking of priority areas for the species in this region. We used the maximum entropy algorithm to model habitat suitability for the jaguar in the Cerrado, with nine uncorrelated environmental variables and 106 non-autocorrelated presence-only records. We prioritized regions, using Zonation, and ranked jaguar conservation units according to their area, proximity to strictly protected areas, jaguar presence, and potential for connectivity. Circa $30 \%$ of the Cerrado is suitable for the jaguar. The most important variables affecting jaguar distribution are mean rainfall and land cover, with a high probability of jaguar presence in forest and savannah. We selected 31 high-priority jaguar conservation units, covering c. $174,825 \mathrm{~km}^{2}(8.5 \%)$ of the Cerrado. We emphasize the need for new protected areas and the promotion of sustainable development, as only $0.4 \%$ of the Cerrado $\left(8,345 \mathrm{~km}^{2}\right)$ has high environmental suitability for jaguars and $<_{1} \%$ of the area covered by jaguar conservation units falls within protected areas. Most jaguar conservation units identified here are relevant for habitat connectivity in Brazil, given their proximity to other critical areas for jaguar conservation in the Caatinga and the Amazon.
\end{abstract}

Keywords Brazil, Cerrado, connectivity, jaguar conservation unit, Maxent, Panthera onca, spatial conservation prioritization

Supplementary material for this article is available at https://doi.org/10.1017/So030605318000972

Marina Peres Portugal (Corresponding author, (1) orcid.org/0000-0001-86433947) Flávio Henrique Guimarães Rodrigues and Claudia Maria Jacobi Universidade Federal de Minas Gerais, Av. Pres. Antônio Carlos, 6627, Belo Horizonte, Mato Grosso 31270-901, Brazil. E-mail marinapport@gmail.com

Ronaldo Gonçalves Morato Instituto Chico Mendes de Conservação da Biodiversidade, Atibaia, Brazil

Katia Maria Paschoaletto Micchi de Barros Ferraz Universidade de São Paulo, Piracicaba, Brazil

Received 12 September 2017. Revision requested 5 January 2018.

Accepted 16 July 2018. First published online 24 May 2019.

\section{Introduction}

T abitat loss and fragmentation are major threats to bio1 diversity, as they affect species' ability to disperse and can lead to local extinctions (Fischer \& Lindenmayer, 2007). Top predators, such as large felids, are vulnerable to habitat loss and fragmentation because they require extensive areas to range, and an abundance of large prey (Ripple et al., 2014). Establishing protected areas and maintaining connectivity between them are valuable approaches to conserve populations of large carnivores in the long term (Taylor et al., 1993; Ripple et al., 2014). Conservationists and natural resource managers often define conservation areas on the basis of large felids because these species are vulnerable to threats, require large spaces and play important roles as umbrella species and top predators (Grigione et al., 2009).

The jaguar Panthera onca once had a broad distribution, from the southern USA to Patagonia, but it now occupies only $51 \%$ of its historical range (Quigley et al., 2017). It has large home ranges, with habitats characterized by the presence of water bodies and sufficient prey, and it prefers natural areas with low anthropogenic disturbance (Vynne et al., 2011; Cullen et al., 2013). These characteristics make it an excellent model species for identifying priority areas for conservation at a landscape scale (Hatten et al., 2005; Grigione et al., 2009; Rodríguez-Soto et al., 2011; Morato et al., 2014).

The jaguar is categorized as Near Threatened on the IUCN Red List (Quigley et al., 2017) but in Brazil, where some populations face significant threats, the species is categorized as Vulnerable (Morato et al., 2013). Jaguars are particularly threatened in the Cerrado biome, with an estimated population decline of $>50 \%$ since 1987 (Moraes, 2012; Morato et al., 2013). The major threats to jaguars in the Cerrado are habitat loss, resulting from high rates of conversion of natural vegetation for pastures and agriculture, prey depletion, and hunting (Moraes, 2012; Morato et al., 2013; Strassburg et al., 2017). The Cerrado has already lost $46 \%$ of its native vegetation (Strassburg et al., 2017) but $<_{3} \%$ of its area is protected against land-cover change (MMA, 2016). This situation threatens the survival not only of the jaguar population but also the c. 4,800 plant and vertebrate species of the biome, many of which are endemic to this biodiversity hotspot (Strassburg et al., 2017).

Several studies have proposed jaguar conservation units, identifying important areas for jaguars across their 
geographical range (Sanderson et al., 2002; Rabinowitz \& Zeller, 2010; Nijhawan, 2012). Jaguar conservation units are defined as areas with a stable prey community that could either maintain a resident jaguar population (a minimum of 50 breeding individuals) or contain fewer individuals but with adequate habitat, where the population could increase if threats were reduced (Sanderson et al., 2002).

Species distribution models have been used to identify areas of high conservation value for large felid species, including the selection of areas suitable for jaguars (Rodríguez-Soto et al., 2011; Morato et al., 2014; Angelieri et al., 2016; Paviolo et al., 2016). They combine information about the geographical occurrence of species and environmental covariates, and can be used to generate maps that show the habitat suitability for the species (Phillips et al., 2006).

We used species distribution models and other analytical tools to evaluate environmental conditions for jaguar conservation in the Brazilian Cerrado. We aimed to (1) assess the current distribution of jaguars in the biome at a fine resolution, according to environmental and anthropogenic conditions, (2) identify and prioritize potential jaguar conservation units, and (3) review proposed management actions in the priority jaguar conservation units. Compared to previous studies, we expected to expand the potentially suitable area for jaguars in the Cerrado, and thus enhance conservation efforts to save the species in this hotspot.

\section{Study area}

The Cerrado (Fig. 1) comprises $2,039,373 \mathrm{~km}^{2}$ of savannah and various types of grasslands and shrublands, as well as tropical, semi-deciduous and deciduous forests (Coutinho, 2000). The climate is seasonal, with rainy summers and dry winters. The mean annual temperature is $22-23{ }^{\circ} \mathrm{C}$ and the mean annual rainfall is $1,200-1,800 \mathrm{~mm}$ (Coutinho, 2000). The Cerrado has a low human population density and a mean human development index (UNDP, 2018) of 0.71 in the principal municipalities. Agriculture and cattle ranching are the main sources of livelihood (Mueller \& Martha, 2008).

\section{Methods}

The methods and workflow used to define jaguar conservation units are outlined in Fig. 2.

\section{Presence records}

The Brazilian National Predator Research Center (Desbiez et al., 2013) provided 126 presence records of jaguars (sightings, captured individuals, confirmed tracks, and faeces; Fig. 1, Supplementary Table 1). These records, which include geographical coordinates, were obtained by jaguar

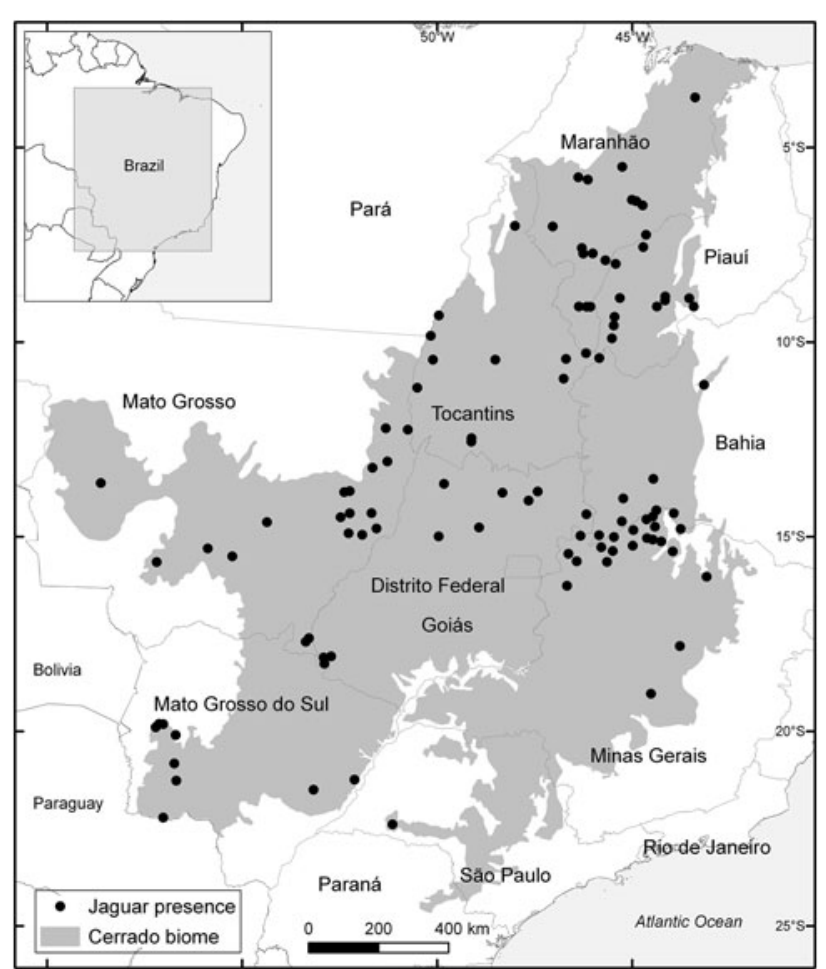

Fig. 1 Locations of 106 jaguar Panthera onca presence records in the Cerrado of Brazil, used to model the habitat suitability for the species.

specialists in the course of field studies in the Cerrado during 2000-2009. To reduce spatial autocorrelation we firstly rarefied presence records of jaguars within a distance of $9 \mathrm{~km}$, which corresponds to the approximate radius of the jaguar's home range $\left(265 \mathrm{~km}^{2}\right)$ in the Cerrado (Astete et al., 2008). We then used the SDMtoolbox in ArcGIS 10.2 (ESRI, Redlands, USA) to calculate the heterogeneity of the first three principal components of 13 continuous environmental layers (Table 1), producing a final heterogeneity layer that allowed us to rarefy records by reducing climate autocorrelation among them (Brown, 2014).

\section{Environmental layers}

We selected 15 environmental layers according to their functional relevance for the species (Table 1; Elith \& Leathwick, 2009; Morato et al., 2014). We used SDMtoolbox (Brown, 2014) to identify Pearson correlations (Pearson's $r<0.5$; Angelieri et al., 2016) between the 13 continuous environmental variables (Table 1, Supplementary Table 2).

\section{Species distribution modelling}

We modelled the current jaguar distribution in the Cerrado biome using Maxent 3.3.3 $k$ (Phillips et al., 


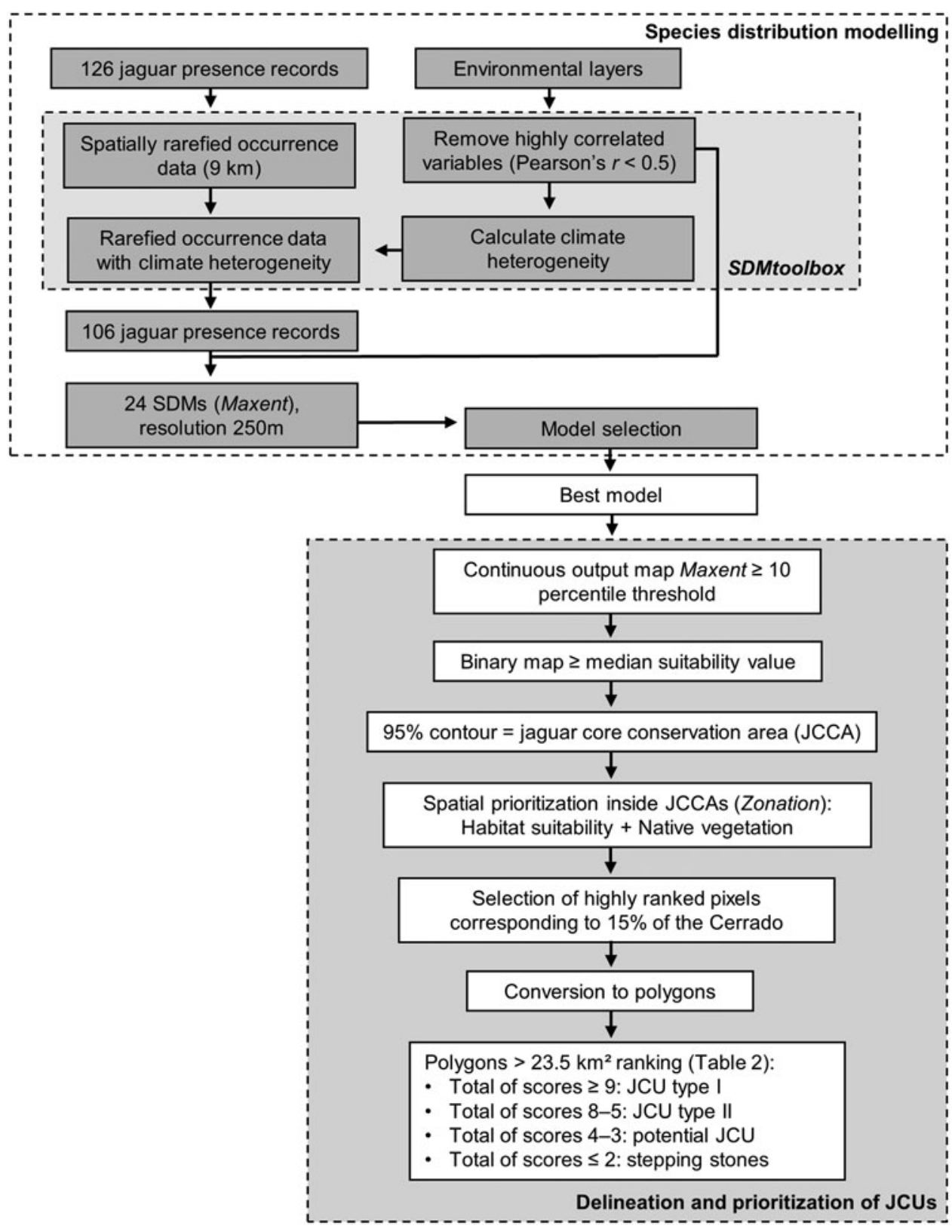

FIG. 2 Methods and workflow used to define jaguar conservation units (JCUs) using species distribution modelling (SDM).
2005, 2006). Maxent is one of the most popular tools for modelling species distribution using only presence data and has been adopted in many studies to identify areas of high conservation value (Fourcade et al., 2014; Morato et al., 2014; Paviolo et al., 2016). In general, it performs better than other algorithms (Peterson et al., 2008; Doko et al., 2011; Rodríguez-Soto et al., 2011). Maxent assumes that the presence of a species at a sample location indicates a favourable set of ecological variables and estimates the closest probability to a uniform distribution (the distribution of maximum entropy; Phillips et al., 2006). Although restricting the range of occurrence of a species may introduce bias in species distribution modelling results
(Barbet-Massin et al., 2010), we decided to use a biome scale because the jaguar distribution in the Atlantic Rainforest has been better predicted using biome databases than continental ones (Ferraz et al., 2012).

We used various combinations of non-correlated layers and generated 24 models in Maxent (Supplementary Material 2). We also ran each model with raw output to calculate Akaike information criteria corrected for small sample sizes (AICc), using the NicheA toolkit (Qiao et al., 2016). We chose AICc based on its top performance in selecting models with small sample sizes (Warren \& Seifert, 2011). We assessed model performance using the area under the receiver operating characteristic curve (AUC), AICc, 
TABLE 1 Environmental variables used in species distribution modelling for the jaguar Panthera onca in the Cerrado (Fig. 1), with their original spatial resolution, year and functional relevance, and sources.

\begin{tabular}{|c|c|c|c|c|}
\hline Environmental variables & $\begin{array}{l}\text { Original } \\
\text { spatial } \\
\text { resolution }^{1}\end{array}$ & Year & Functional relevance & Source \\
\hline${ }^{\star}$ Mean annual temperature & $90 \mathrm{~m}$ & 2012 & $\begin{array}{l}\text { Used to characterize climate, which can } \\
\text { influence felid \& prey activities } \\
\text { (Astete et al., 2008) }\end{array}$ & Alvares et al. (2013a) \\
\hline${ }^{\star}$ Mean annual rainfall & $90 \mathrm{~m}$ & 2013 & $\begin{array}{l}\text { Used to characterize climate, which can } \\
\text { influence felid \& prey activities } \\
\text { (Astete et al., 2008) }\end{array}$ & Alvares et al. (2013b) \\
\hline Land cover & $1: 250,000$ & $2009-2010$ & $\begin{array}{l}\text { Jaguars prefer forested areas \& areas near } \\
\text { rivers. They avoid human disturbance, } \\
\text { selecting areas with a high proportion of } \\
\text { natural habitat \& a high proportion of } \\
\text { closed canopy (Vynne et al., 2011) }\end{array}$ & $\begin{array}{l}\text { Vegetation map of } 2002 \\
\text { updated to } 2009 / 2010 \\
\text { (Supplementary } \\
\text { Material 1) }\end{array}$ \\
\hline${ }^{\star}$ Elevation & $90 \mathrm{~m}$ & 2008 & $\begin{array}{l}\text { Most important factor in a jaguar species } \\
\text { distribution model for the Caatinga } \\
\text { biome, with low human activity in } \\
\text { high-elevation areas (Morato et al., } \\
\text { 2014) }\end{array}$ & $\begin{array}{l}\text { CGIAR Consortium } \\
(2008)\end{array}$ \\
\hline Vegetation height & $30 \mathrm{~m}$ & 2007 & $\begin{array}{l}\text { Can be an indicator of canopy cover, } \\
\text { which has been associated with } \\
\text { probability of jaguar presence } \\
\text { (Vynne et al., 2011) }\end{array}$ & $\begin{array}{l}\text { Woods Hole Research } \\
\text { Center (2007) }\end{array}$ \\
\hline $\begin{array}{l}{ }^{\star} \text { Euclidean distance from } \\
\text { water } \&{ }^{*} \text { density of } \\
\text { drainage }\end{array}$ & $1: 250,000$ & 2013 & $\begin{array}{l}\text { Known to influence jaguar occurrence } \\
\text { (Morato et al., 2014) }\end{array}$ & HydroWeb (2010) \\
\hline $\begin{array}{l}\text { * Euclidean distance from } \\
\text { urban areas }\end{array}$ & $1: 250,000$ & 2008 & $\begin{array}{l}\text { Indicates distance to human activities, } \\
\text { which negatively influence the presence } \\
\text { of jaguars (De Angelo et al., 2011) }\end{array}$ & $\begin{array}{l}\text { Urban areas identified } \\
\text { in the land-cover map }\end{array}$ \\
\hline${ }^{\star}$ Slope $\&{ }^{\star}$ terrain ruggedness & $90 \mathrm{~m}$ & 2008 & $\begin{array}{l}\text { Can affect the movement of some } \\
\text { predators \& prey (Laporte et al., 2010) }\end{array}$ & Sappington et al. (2007) \\
\hline $\begin{array}{l}\text { Temporal enhanced } \\
\text { vegetation index } \\
\left({ }^{*} \text { maximum, }{ }^{*} \text { minimum, }\right. \\
{ }^{\star} \text { mean, }{ }^{*} \text { rainy } \\
\text { (Oct.-Mar.) \& }{ }^{*} \text { dry } \\
\text { (Apr.-Sep.) dry seasons) }\end{array}$ & $250 \mathrm{~m}$ & 2013 & $\begin{array}{l}\text { Used as a proxy for primary produc- } \\
\text { tivity, as ungulates (the main prey of } \\
\text { jaguars in the Cerrado; Astete et al., } \\
\text { 2008) respond to primary productivity } \\
\text { (Pettorelli et al., 2011) }\end{array}$ & LAPIG (2013) \\
\hline
\end{tabular}

${ }^{1}$ We used a spatial resolution of $250 \mathrm{~m}$ for modelling. Where required, resolutions were resampled with the nearest neighbour assignment for continuous layers and the majority resampling technique for categorical layers.

*The 13 continuous environmental variables.

binomial probability, and omission error (Pearson, 2010; Supplementary Material 2). We also interpreted the marginal curves of the variables that most influenced the models; these are plots created by Maxent that reflect the dependence of predicted suitability both on the selected variable and on dependencies induced by correlations between the selected variable and other variables (Pearson, 2010).

We used an independent dataset of 23 jaguar occurrences from the National Predator Research Center (Supplementary Table 3), for 2007-2017, to validate our final model. Jaguar occurrence was predicted correctly if records were within a radius of $9 \mathrm{~km}$ of suitable pixels, the same distance used to rarefy records, confirming that pixels were within the potential home range of the individuals.
KF, RGM and FHGR also analysed the final model visually and validated the results.

\section{Jaguar conservation units}

We used the best model to select pixels equal to or higher than the median suitability value of the final species distribution model (Rodríguez-Soto et al., 2011; Morato et al., 2014) and select highly suitable areas. As the jaguar is a threatened species, we generated polygons using $95 \%$ of the volume contour of the isopleth function (Beyer, 2012) to guarantee that areas with high and medium suitability would be selected, thus avoiding restricting prioritization of jaguar conservation units to high suitability areas only. 
We designated all polygons jaguar conservation core areas; i.e. large areas with medium or high environmental suitability for jaguars.

We used Zonation (Moilanen, 2007), for spatial conservation prioritization, to define jaguar conservation units within each jaguar conservation core area. Zonation removes cells of multiple environmental layers interactively and provides a map with the smallest aggregate marginal loss of environmental characteristics (Lehtomäki \& Moilanen, 2013). We ran Zonation combining the habitat suitability map within jaguar conservation core areas, which we assigned a weight of 1 , and areas with natural vegetation (from the land-cover map), which we assigned a weight of zero, using the additive benefit function (Lehtomäki \& Moilanen, 2013). We used different weights to avoid selecting pixels with suitable vegetation but no jaguar occurrence. We used a warp factor of 100 , allowing edge removal and distribution smoothing to obtain a more compact solution. From this ranked output we selected the percentage that represented $15 \%$ of the Cerrado area $\left(305,905 \mathrm{~km}^{2}\right)$, similar to the current extent of protected areas in the world (Albuquerque \& Beier, 2015).

We transformed this final zonation raster into polygons and assessed those $>23.5 \mathrm{~km}^{2}$ in area according to the ranking of parameters in Table 2, to prioritize jaguar conservation units. We used the area of the jaguar conservation unit and the presence of jaguars, according to the concept of jaguar conservation units established by Sanderson et al. (2002). We added the categories proximity to protected areas and potential connectivity, as we aimed to select jaguar conservation units that would connect to other patches. The potential for connectivity is based on the probability of connectivity index, which examines an attribute of the patch (mean habitat suitability value, in this case) and the maximum product probability of all paths between a pair of patches, calculated using Conefor 2.6 (Saura \& Torné, 2009). This probability was based on the mean dispersal distance ( 0.5 probability), calculated as $113 \mathrm{~km}$ according to the formula $17 \times \sqrt{ }$ home range (Bowman et al., 2002). We assumed this number to be plausible, as there is no dispersal distance available for the jaguar in the Cerrado.

Each polygon was then assigned a score for each category (Table 2) and the polygons were categorized into four types based on the sum of the scores: (1) high-priority jaguar conservation units, with a score of $\geq 9$; (2) medium-priority jaguar conservation units, with a score of $5-8$; (3) lowpriority jaguar conservation units, with a score of $3-4$; and (4) stepping stones between jaguar conservation units, with a score of $\leq 2$.

For the final jaguar conservation units, we estimated the mean jaguar population according to the lowest and highest recent estimates ( 0.29 and 0.62 per $100 \mathrm{~km}^{2}$, respectively) for Emas National Park (Sollmann et al., 2011). We grouped the units into areas according to their distribution in the
Cerrado, and then overlapped them with areas suggested by the Brazilian government for biodiversity conservation, to identify and review the conservation actions already indicated for the geographical regions of priority jaguar conservation units (MMA, 2015). All spatial analyses and geoprocessing were conducted in ArcGIS.

\section{Results}

The best distribution model (AUC test $=0.805 \pm$ SD 0.046 , omission error $=0.209, \mathrm{P}=0.002)$ used 106 occurrence points and nine environmental layers. It identified $30 \%$ of the Cerrado (c. $687,059 \mathrm{~km}^{2}$ ) as being suitable for the jaguar (Fig. 3a). The model was accurate: $95.23 \%$ of the additional records used only for validation were predicted correctly. However, only $0.4 \%$ of the biome $\left(8,345 \mathrm{~km}^{2}\right)$ showed high suitability $(>0.7)$ for the species. These areas were located primarily in the north-east of the biome and in small areas in the north-west, near the Amazon biome.

The variables that best predicted jaguar distribution in the Cerrado were mean rainfall (Table 3, Fig. 4) and land cover (Table 3, Fig. 5). The probability of jaguar presence was high in areas with $300-1,400 \mathrm{~mm}$ of rainfall; i.e. near the Caatinga biome, a semi-arid region of Brazil. There was also a high probability of jaguar presence in areas with 2,000 mm of rainfall, near the Amazon biome. Forest areas (open evergreen upper plains forest and forested grassland savannah) had a high probability of jaguar presence, followed by some savannah types and secondary vegetation. The probability of jaguar presence in human-modified areas was low to medium (Fig. 5). Maximum enhanced vegetation index, forest height, and mean annual temperature also contributed significantly to the model (Supplementary Material 3 ).

We identified 62 jaguar core conservation areas $\left(555,796 \mathrm{~km}^{2}\right.$; Fig. 3 b), covering $27 \%$ of the Cerrado. Within these areas we identified 427 jaguar conservation units, covering $10 \%$ of the biome $\left(219,100 \mathrm{~km}^{2}\right)$. Most reserves were medium or low-priority jaguar conservation units because of their small area $\left(<2 \mathrm{~km}^{2}\right)$ and distance from strictly protected areas $(>113 \mathrm{~km})$, with absence of jaguar records within a radius of up to $30 \mathrm{~km}$ and low importance for connectivity. Only $23,662 \mathrm{~km}^{2}$ ( $1 \%$ of the Cerrado) of the jaguar conservation units are within strictly protected areas.

The ranking of jaguar conservation units prioritized 31 units (Fig. 6), in five areas (Table 4). Only 12 units overlapped with an existing strictly protected area. High-priority jaguar conservation units covered $8.5 \%$ of the Cerrado biome $\left(174,825 \mathrm{~km}^{2}\right)$. Only four units could sustain a viable population ( $\geq 50$ individuals) and 24 could sustain two or more individuals (Table 4). Three units could not sustain a mating pair but were ranked highly because of jaguar presence records inside the polygon, or high connectivity importance. Most high-priority units are within the areas of the Cerrado that the Brazilian government recognizes as 
TABLE 2 Ranking of parameters used for prioritization of jaguar conservation units in the Cerrado.

\begin{tabular}{|c|c|c|c|}
\hline Category & Parameter & Score & Justification \\
\hline \multirow[t]{3}{*}{ Jaguar conservation unit area } & $23.5-265 \mathrm{~km}^{2}$ & 0 & $\begin{array}{l}\text { Regions smaller than the home range of a jaguar mating } \\
\text { pair }\left(265 \mathrm{~km}^{2}, 1 \text { male \& } 2 \text { females; Astete et al., 2008) }\right. \\
\text { that could serve as stepping stones (depending on the } \\
\text { proximity to other patches \& presence of jaguars nearby) }\end{array}$ \\
\hline & $266-5,000 \mathrm{~km}^{2}$ & 2 & $\begin{array}{l}\text { Regions larger than the home range of a jaguar mating } \\
\text { pair but not large enough to maintain a population of } \\
50 \text { individuals }\left(5,000 \mathrm{~km}^{2} \text {, a rounded calculation based }\right. \\
\text { on the home range used) }\end{array}$ \\
\hline & $>5,000 \mathrm{~km}^{2}$ & 4 & $\begin{array}{l}\text { Regions that can maintain a viable population of } 50 \\
\text { individuals }\left(5,000 \mathrm{~km}^{2} \text {, a rounded calculation based on }\right. \\
\text { the home range used) }\end{array}$ \\
\hline \multirow[t]{4}{*}{$\begin{array}{l}\text { Proximity to strictly protected areas, } \\
\text { equivalent to IUCN Categories I, II \& } \\
\text { III (Rylands \& Brandon, 2005) }\end{array}$} & $0-30 \mathrm{~km}$ & 0 & $\begin{array}{l}\text { Individuals in a jaguar conservation unit could also use } \\
\text { the protected area, as it is within the maximum dis- } \\
\text { tance of occasional movement ( } 30 \mathrm{~km} \text {; Cullen, 2006); } \\
\text { this unit is not a priority for conservation in the whole } \\
\text { biome but can have local importance }\end{array}$ \\
\hline & $31-113 \mathrm{~km}$ & 1 & $\begin{array}{l}\text { Protected area is not close enough to be part of the } \\
\text { home range of jaguars inhabiting jaguar conservation } \\
\text { units but is still reachable by jaguars dispersing among } \\
\text { patches; values correspond to the maximum distance } \\
\text { of occasional movements observed by Cullen (2006) } \\
\text { \& the mean dispersal distance calculated following } \\
\text { Bowman et al. (2002) }\end{array}$ \\
\hline & $>113 \mathrm{~km}$ & 0 & $\begin{array}{l}\text { Regions are not a priority because they are separated } \\
\text { by a distance greater than the mean dispersal distance }\end{array}$ \\
\hline & $\begin{array}{l}\text { Located in a jaguar core } \\
\text { conservation area with no } \\
\text { protected area }\end{array}$ & 2 & $\begin{array}{l}\text { Areas without legal protection within an area consid- } \\
\text { ered to be relevant for jaguars in the biome (regardless } \\
\text { of distances to protected areas) }\end{array}$ \\
\hline \multirow[t]{3}{*}{ Presence of jaguars } & $\begin{array}{l}\text { Record inside jaguar core } \\
\text { conservation area }\end{array}$ & 1 & $\begin{array}{l}\text { These regions may be important to other jaguar indi- } \\
\text { viduals of the subpopulation as they have suitable areas } \\
\text { for the species survival, despite not being inside the } \\
\text { home ranges of the jaguars recorded }\end{array}$ \\
\hline & $\begin{array}{l}\text { Record up to } 30 \mathrm{~km} \text { from } \\
\text { jaguar conservation unit }\end{array}$ & 3 & $\begin{array}{l}\text { Maximum distance at which the jaguar conservation } \\
\text { unit may be considered to be within the home range of } \\
\text { the jaguar recorded, based on } 97.5 \% \text { of the radius of } \\
\text { jaguar home range in the Cerrado (Sollmann et al., } \\
\text { 2011); this distance is the maximum distance of } \\
\text { occasional movements (Cullen, 2006) }\end{array}$ \\
\hline & $\begin{array}{l}\text { Record inside jaguar } \\
\text { conservation unit }\end{array}$ & 6 & $\begin{array}{l}\text { Paramount region for these individuals \& probably } \\
\text { others that live nearby }\end{array}$ \\
\hline \multirow{4}{*}{$\begin{array}{l}\text { Potential for connectivity (according to } \\
\text { the probability of connectivity index, } \\
\text { PC) }\end{array}$} & $\mathrm{PC}<0.1$ & 0 & Non-priority regions in the Cerrado \\
\hline & $0.1<\mathrm{PC}<0.5$ & 2 & $\begin{array}{l}\text { Low-importance regions for the connectivity of all } \\
\text { areas in the Cerrado }\end{array}$ \\
\hline & $0.5<\mathrm{PC}<1$ & 4 & $\begin{array}{l}\text { Medium-importance regions for the connectivity of } \\
\text { all areas in the Cerrado }\end{array}$ \\
\hline & $\mathrm{PC}>1$ & 6 & $\begin{array}{l}\text { High-importance regions for the connectivity of all } \\
\text { areas in the Cerrado }\end{array}$ \\
\hline
\end{tabular}

being important for conservation (MMA, 2015), although they are not strictly protected, with 22 units categorized as being of high, very high or extremely high importance (Table 4). Most high-priority jaguar conservation units also lie within areas where the government recognizes the need to establish new reserves (strictly protected or sustainable use), and 11 are in areas where a mosaic of parks or corridors is desirable (Table 4 ).

\section{Discussion}

Our results indicate there are still suitable areas for jaguars in $30 \%$ of the Cerrado but highly suitable areas are scarce. Our model identified more jaguar conservation units than previous studies in this biome (Sanderson et al., 2002; Zeller, 2007; Desbiez et al., 2013), increasing the total area of high-priority jaguar conservation units to $174,825 \mathrm{~km}^{2}$, 

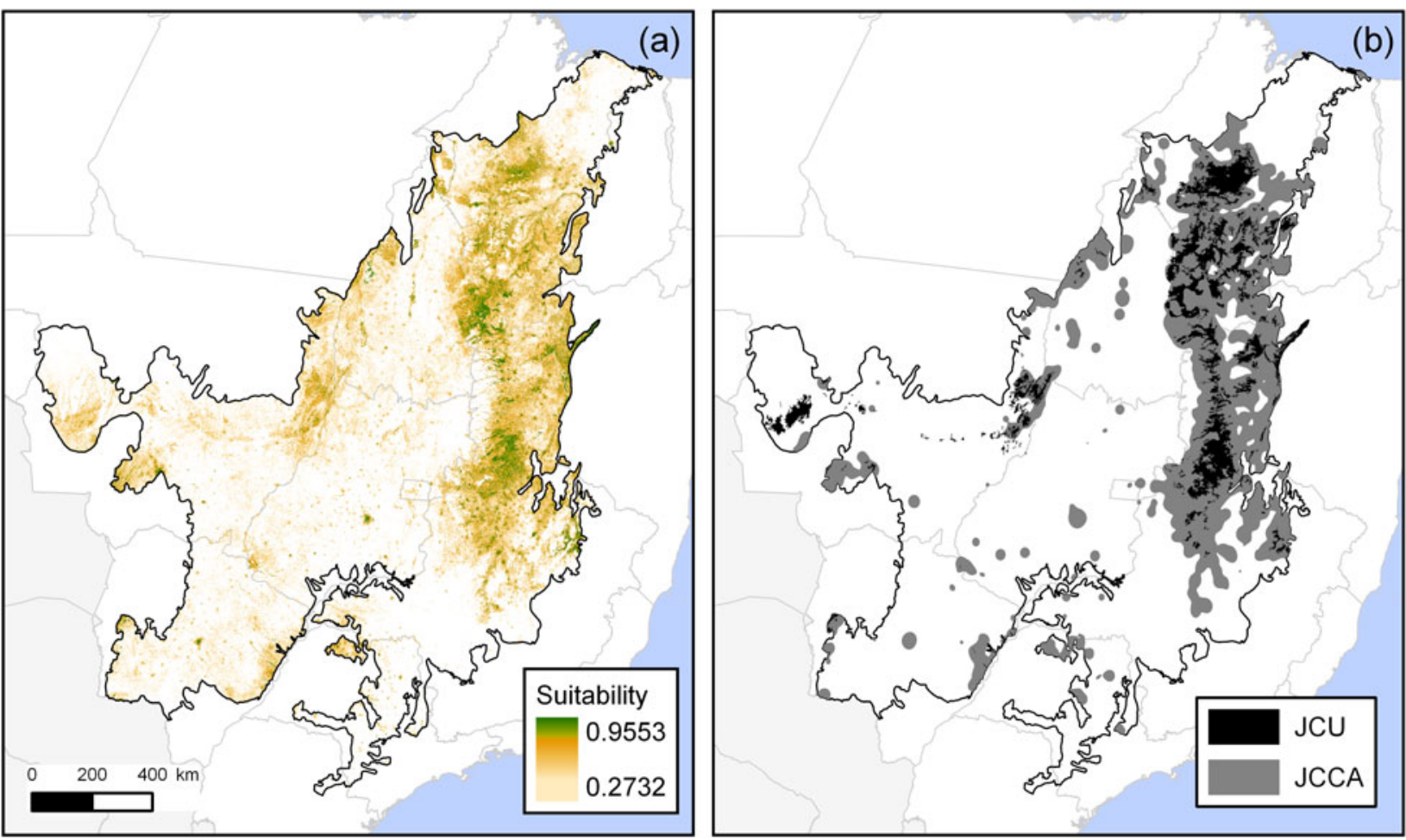

FIG. 3 (a) Habitat suitability for the jaguar, identified by species distribution modelling, and (b) all jaguar conservation units (JCUs) and jaguar core conservation areas (JCCAs) in the Cerrado biome (Fig. 1).

TABLE 3 Importance of the environmental variables for the final model, evaluated by per cent contribution and permutation importance.

\begin{tabular}{lll}
\hline Variable & \% contribution & $\begin{array}{l}\text { Permutation } \\
\text { importance }\end{array}$ \\
\hline Mean annual rainfall & 21.7 & 25.5 \\
Land cover & 19.4 & 10.0 \\
Maximum enhanced vegetation & 14.4 & 16.3 \\
$\quad$ index & & \\
Forest height & 13.2 & 7.2 \\
Mean annual temperature & 11.1 & 17.5 \\
Euclidean distance from urban & 8.0 & 7.6 \\
$\quad$ areas & & \\
Ruggedness & 4.9 & 7.9 \\
Euclidean distance from water & 4.2 & 3.1 \\
Minimum enhanced vegetation & 3.0 & 5.0 \\
$\quad$ index & & \\
\hline
\end{tabular}

$16 \%$ more than the largest previous estimate (Desbiez et al., 2013). In general, our model identified similar appropriate regions to those of the National Action Plan for jaguar conservation (Desbiez et al., 2013), based on 1-km-resolution layers with various environmental data. There is a concentration of highly suitable areas in the eastern corridor of the Cerrado, which, with proper management, could connect 23 jaguar conservation units.

Annual rainfall and land cover, the most important environmental variables correlated with jaguar presence, were

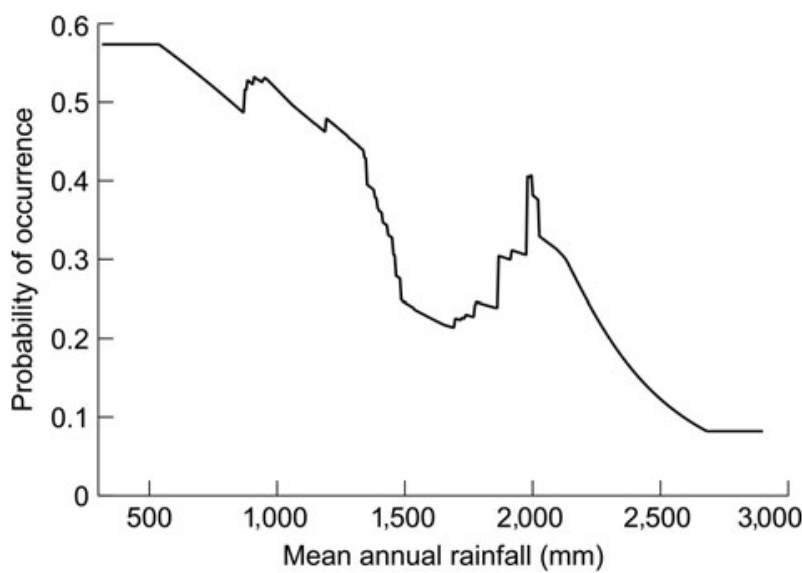

FIG. 4 Marginal response curve of mean annual rainfall, the variable that contributed most to the jaguar distribution model for the Cerrado.

also the environmental covariates that best explained jaguar occurrence in the Cerrado in an earlier study (Desbiez et al., 2013). The low probability of jaguar presence in areas that received $1,500-1,800 \mathrm{~mm}$ of rainfall probably reflects vegetation loss. This rainfall range matches areas that have been devastated by monoculture and extensive deforestation (Coutinho, 2000). Regions with a high probability of jaguar presence comprise suitable habitats with native vegetation near the Caatinga biome $(320-1,400 \mathrm{~mm}$ rainfall), in the north-eastern Cerrado, where there is lower annual rainfall, 


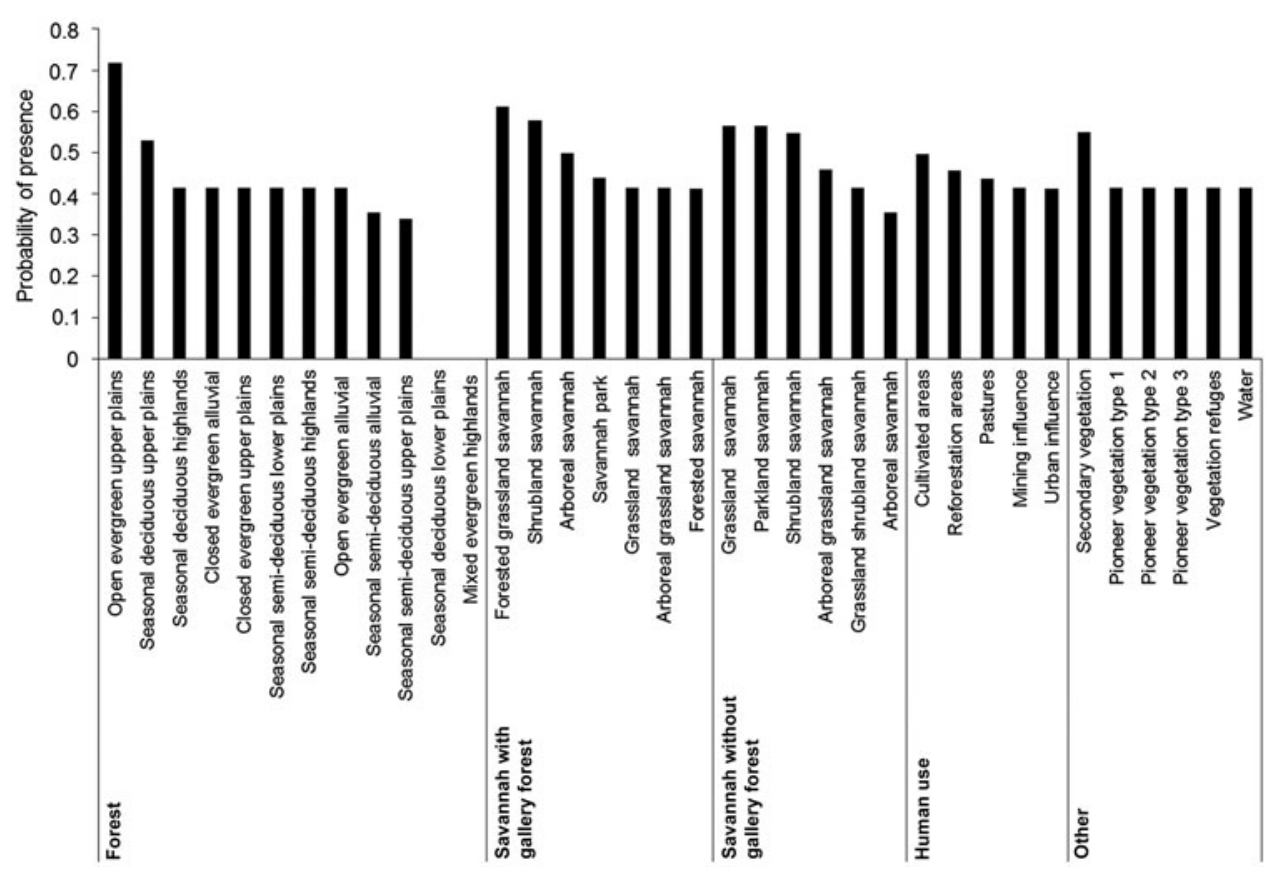

FIG. 5 Probability of jaguar presence in the Cerrado by land-cover type.

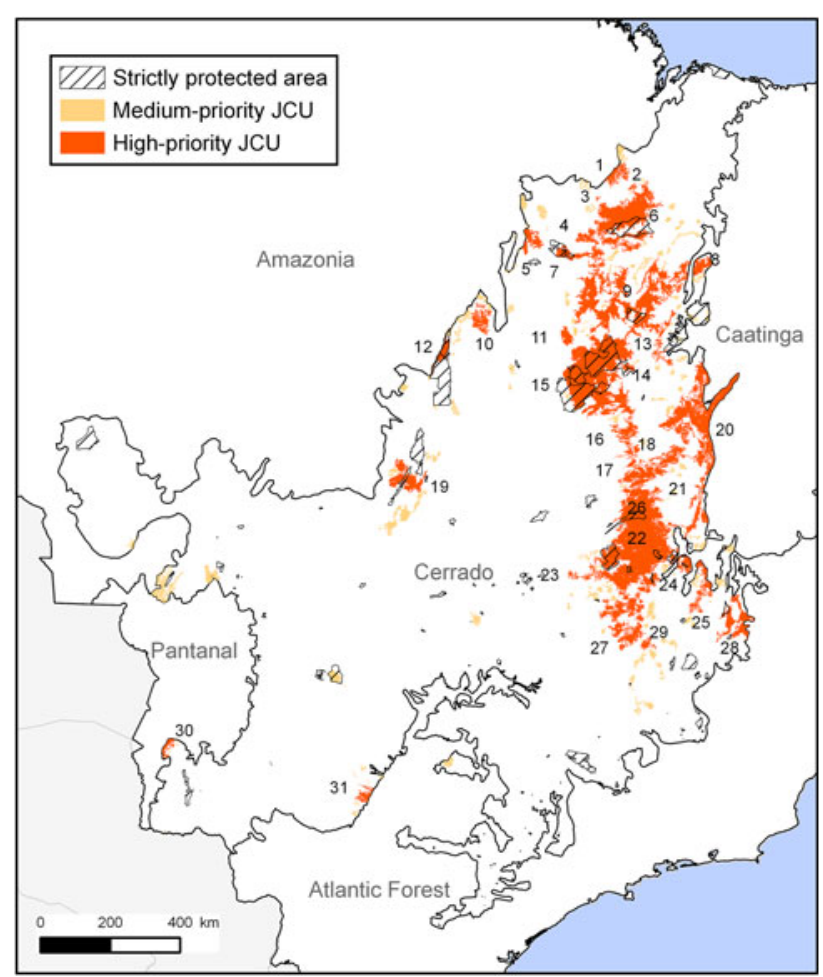

FIG. 6 Priority ranking of jaguar conservation units (the numbers refer to the 31 high-priority units listed in Table 4), and locations of existing strictly protected areas.

and areas near the Amazon biome, in the western Cerrado (c. 2,000 mm).

The land-cover types most correlated with jaguar presence in our models were similar to those found by Vynne et al. (2011), who observed that jaguars preferred areas with native vegetation and avoided pastures and plantations, and found that jaguars selected areas of shrubland and grassland savannahs as well as forests. The high probability of jaguar presence in the forested grassland savannah with gallery forest indicates a preference for areas near water, which has been reported previously (Vynne et al., 2011). Although several studies have shown that jaguars prefer primary forests when they are available (Cullen et al., 2013), our model also indicated that secondary vegetation could have a positive influence on their occurrence. This reinforces the importance of including secondary vegetation and devising restoration actions for the maintenance of jaguar habitats.

Other variables that contributed significantly to the model (e.g. maximum enhanced vegetation index, forest height, mean annual temperature; Supplementary Material 3), indicate a high probability of jaguar occurrence in areas of savannah vegetation. The strong preference for areas with low vegetation height, high mean annual temperatures, and low maximum enhanced vegetation index coincides with characteristics of areas covered by savannah vegetation (Coutinho, 2000; Bayma \& Sano, 2015), and therefore those areas should be preserved for jaguar conservation in the Cerrado.

Despite our effort to select functional environmental predictors, species distribution models characterize only part of the species' environmental niche and may lead to biased predictions about habitat suitability (Barbet-Massin et al., 2010). Our model identified jaguar core conservation areas similar to jaguar occupancy areas identified by Moraes (2012) and Zeller (2007), and increased some areas in the north-eastern Cerrado. However, our model omitted an area identified by Moraes (2012) and Zeller (2007) for jaguar 
TABLE 4 High-priority jaguar conservation units in the Cerrado biome (Fig. 6). Units with confirmed jaguar occurrence are indicated with an asterisk.

\begin{tabular}{|c|c|c|c|c|}
\hline Jaguar conservation unit & Area $\left(\mathrm{km}^{2}\right)^{1}$ & $\begin{array}{l}\text { Mean estimated } \\
\text { potential } \\
\text { population size (range) }\end{array}$ & $\begin{array}{l}\text { Ranking } \\
\text { score }\end{array}$ & $\begin{array}{l}\text { Government recommended } \\
\text { actions }^{2}\end{array}$ \\
\hline \multicolumn{5}{|l|}{ Amazonian border } \\
\hline 1 & $1,959.59$ & $8.92(5.68-12.15)$ & 12 & $\mathrm{R}, \mathrm{PS}$ \\
\hline $5^{*}$ & $1,909.30$ & $8.69(5.54-11.84)$ & 16 & $\mathrm{P}$ \\
\hline 10 & $2,413.83$ & $10.98(7.00-14.97)$ & 10 & $\mathrm{P}$ \\
\hline $12^{*}$ & $1,279.28$ & $5.82(3.71-7.93)$ & 12 & PS, SI \\
\hline $19^{*}$ & $4,035.55$ & $18.36(11.70-25.02)$ & 12 & SU, PS, MC, SI, R \\
\hline \multicolumn{5}{|l|}{ Cerrado eastern corridor } \\
\hline $2^{*}$ & 254.58 & $1.16(0.74-1.58)$ & 9 & \\
\hline $3^{*}$ & 92.94 & $0.42(0.27-0.58)$ & 9 & \\
\hline 4 & $1,488.96$ & $6.77(4.32-9.23)$ & 10 & \\
\hline $6^{*}$ & $15,412.34$ & $70.13(44.70-95.56)$ & 16 & $\mathrm{R}, \mathrm{PS}, \mathrm{MC}, \mathrm{P}, \mathrm{SU}$ \\
\hline $7^{*}$ & $2,637.51$ & $12.00(7.65-16.35)$ & 11 & $\mathrm{P}, \mathrm{MC}$ \\
\hline 8 & $1,538.20$ & $7.00(4.46-9.54)$ & 10 & \\
\hline 9 & $1,420.79$ & $6.46(4.12-8.81)$ & 10 & \\
\hline 11 & $1,180.57$ & $5.37(3.42-7.32)$ & 10 & \\
\hline 13 & $1,179.68$ & $5.37(3.42-7.31)$ & 9 & $\mathrm{R}$ \\
\hline 14 & 588.27 & $2.68(1.71-3.65)$ & 9 & $\mathrm{R}$ \\
\hline $15^{*}$ & $51,641.50$ & $234.97(149.76-320.18)$ & 16 & R, P, PS, CR, MC, SI \\
\hline 16 & $2,429.84$ & $11.06(7.05-15.07)$ & 10 & PS, P \\
\hline 17 & 860.28 & $3.91(2.49-5.33)$ & 9 & PS, P \\
\hline 18 & 424.60 & $1.93(1.23-2.63)$ & 10 & \\
\hline $20^{*}$ & $16,433.74$ & $74.77(47.66-101.89)$ & 17 & $\mathrm{P}, \mathrm{PS}, \mathrm{MC}$ \\
\hline 21 & $3,033.45$ & $13.80(8.80-18.81)$ & 11 & PS, MC, R, SI, CR \\
\hline $22^{*}$ & 458.80 & $2.09(1.33-2.84)$ & 14 & SI, PS, MC, SU \\
\hline $23^{*}$ & 711.74 & $3.24(2.06-4.41)$ & 13 & $\mathrm{R}, \mathrm{PS}$ \\
\hline $24^{*}$ & $1,210.13$ & $5.51(3.51-7.50)$ & 14 & CR, MC, SI, R \\
\hline 25 & $2,559.01$ & $11.64(7.42-15.87)$ & 12 & $\mathrm{R}, \mathrm{PS}$ \\
\hline $26^{*}$ & $47,752.10$ & $217.27(138.48-296.06)$ & 16 & R, MC, P, PS, CR, SI \\
\hline 27 & $3,385.54$ & $15.40(9.82-20.99)$ & 10 & \\
\hline 29 & 694.97 & $3.16(2.02-4.31)$ & 10 & $\mathrm{CR}, \mathrm{R}$ \\
\hline \multicolumn{5}{|l|}{ Pantanal border } \\
\hline $30^{*}$ & 728.20 & $3.31(2.11-4.51)$ & 10 & SI \\
\hline \multicolumn{5}{|l|}{ Atlantic Forest border } \\
\hline 28 & $4,089.50$ & $18.61(11.86-25.35)$ & 9 & PS, MC, SI \\
\hline $31^{*}$ & $1,020.88$ & $4.64(2.96-6.33)$ & 10 & PS, MC \\
\hline
\end{tabular}

${ }^{1}$ Includes adjacent areas that are already strictly protected.

${ }^{2} \mathrm{R}$, restoration actions; PS, promote sustainability; P, territorial planning; SI, creation of strictly protected reserves; SU, creation of sustainable-use reserves (equivalent to IUCN categories IV, V \& VI; Rylands \& Brandon, 2005); CR, creation of reserves of any type; MC, establishment of a mosaic of parks or corridors (MMA, 2015).

conservation in Goiás and Tocantins states, because of low environmental suitability, despite its native vegetation. Nonetheless, this area should be considered in jaguar conservation plans because, besides its regional importance, it may be relevant for connecting jaguar conservation units in the northern Cerrado.

We identified 31 high-priority jaguar conservation units (occupying 174,825 $\mathrm{km}^{2}$ ) in the Cerrado, compared to previous studies that identified five to seven units (occupying c. $130,000 \mathrm{~km}^{2}$; Sanderson et al., 2002; Zeller, 2007). Units of medium and low priority can still improve total extension and connectivity among jaguar conservation units. Not all jaguar conservation units have confirmed records of resident jaguars within their limits but most are in regions where we presume jaguars are present.

Jaguar conservation units in the northern and northeastern Cerrado may be vital for maintaining the connectivity between the Amazon and Caatinga biomes and preventing genetic losses among populations. Recent studies reported the effects of habitat deterioration on jaguar genetics in the Caatinga and Atlantic Forest (Haag et al., 2010; Roques et al., 2016). The Amazon, Cerrado and Pantanal populations still maintain good genetic diversity, but the genetic connectivity in central areas of Brazil, mainly the Cerrado, needs to be maintained to avoid further declines (Roques et al., 2016). Preserving the connectivity between 
jaguar conservation units in the Cerrado may prevent genetic losses in this biome.

The Cerrado eastern corridor, which encompasses the largest jaguar conservation units, is particularly threatened because it lies in the new soybean frontier referred to as MaToPiBa, a region with cheap land, which accounted for $10 \%$ of Brazilian soybean production during 2011-2012 (Reynolds, 2012). We recommend that actions listed in Table 4, such as the creation of new strictly protected areas and corridors, be implemented as soon as possible to preserve jaguar conservation units in these regions (Moraes, 2012; Desbiez et al., 2013). We also recommend the creation of new protected areas and corridors for those jaguar conservation units in areas for which the Brazilian government has no suggested actions.

The Cerrado has $8.2 \%$ of its territory protected but $<3 \%$ is within strictly protected areas (MMA, 2016). Many of the jaguar conservation units are in regions where the government has recommended the creation of new strictly protected areas, which would alleviate threats to the jaguar's survival and habitat. Some jaguar conservation units are in regions where the government advocates the creation of sustainable-use protected areas (MMA, 2015), where jaguars could persist with adequate sustainable use, proper management and controlled land-cover change. However, half of the sustainable-use protected areas in the Cerrado are in the category 'environmentally protected areas' (IUCN category V), which allows agriculture, pastures and other human uses and considers biodiversity conservation a secondary aim (Rylands \& Brandon, 2005). Although other types of sustainable-use protected areas could be adequate for jaguar conservation because of lower human occupation and habitat impact (Rylands \& Brandon, 2005), environmentally protected areas may not be the best type for jaguar conservation. This category may include a negligible portion of natural habitat, as well as threats to jaguars, including vehicular traffic, poaching and habitat fragmentation (Vynne et al., 2011; Morato et al., 2013). Jaguar conservation could be feasible in protected areas of this category if their management plans alleviated these threats and specified areas with restricted use.

Less than $1 \%$ of the jaguar conservation units we identified in the Cerrado are within strictly protected areas, and therefore we recommend new protected areas should be created to improve the conservation of jaguars in this biome and at a continental scale. The expansion of protected areas coupled with political actions, including law enforcement, could slow the rate of deforestation, protecting native habitats (Nepstad et al., 2014) and other species. The Cerrado has 430 threatened faunal species (ICMBIO, 2014), including large mammals that are jaguar prey (e.g. Tayassu pecari and Myrmecophaga tridactyla; Astete et al., 2008). Maintaining jaguar conservation units, and connectivity between them, could contribute to the conservation of biodiversity at all levels.
Acknowledgments We thank the National Council for Scientific and Technological Development for a $\mathrm{PhD}$ scholarship to MPP (Proc. 141266/2013-9) and productivity scholarships to CMJ (Proc. 305403/2013-3), FHGR (Proc. 306695/2015-4), KMPMBF (Proc. 308503/2014-7) and RGM (301652/2015-5), the National Predator Research Center, Chico Mendes Biodiversity Conservation Institute, the collaborators of the National Conservation Action Plan for the Jaguar, the SISBIO database, Rafael Aarão, José Roberto Moreira, Marina Motta Carvalho and Leo Caetano for providing jaguar records, Milton Ribeiro for methodological advice, and Thiago Vieira and Carol Couto for updating the land-cover map.

Author contributions Research lead, writing: MPP; technical advice, writing, revision: RGM, KMPMBF, FHGR, CMJ.

\section{Conflicts of interest None.}

Ethical standards This research abided by the Oryx Code of Conduct.

\section{References}

Albuquerque, F. \& Beier, P. (2015) Global patterns and environmental correlates of high-priority conservation areas for vertebrates. Journal of Biogeography, 42, 1397-1405.

Alvares, C.A., Stape, J.L., Sentelhas, P.C. \& de Moraes Gonçalves, J.L. (2013a) Modeling monthly mean air temperature for Brazil. Theoretical and Applied Climatology, 113, 407-427.

Alvares, C.A., Stape, J.L., Sentelhas, P.C., De Moraes Gonçalves, J.L. \& Sparovek, G. (2013b) Köppen's climate classification map for Brazil. Meteorologische Zeitschrift, 22, 711-728. Angelieri, C.C.S., Adams-Hosking, C., Ferraz, K.M.P.M.B., De Souza, M.P. \& McAlpine, C.A. (2016) Using species distribution models to predict potential landscape restoration effects on puma conservation. PLOS ONE, 11, e0145232.

Astete, S., Sollmann, R. \& Silveira, L. (2008) Comparative ecology of jaguars in Brazil. CAT News, Special issue 4, 9-14.

Barbet-Massin, M., Thuiller, W. \& Jiguet, F. (2010) How much do we overestimate future local extinction rates when restricting the range of occurrence data in climate suitability models? Ecography, $33,878-886$.

BAyma, A.P. \& SANo, E.E. (2015) Séries temporais de índices de vegetação (NDVI e EVI) do sensor MODIS para detecção de desmatamentos no bioma cerrado. Boletim de Ciencias Geodesicas, 21, 797-893.

Beyer, H.L. (2012) Geospatial Modelling Environment. Http://www. spatialecology.com/gme [accessed 15 December 2013].

Bowman, J., Jaeger, J.A.G. \& Fahrig, L. (2002) Dispersal distance of mammals is proportional to home range size. Ecology, 83, 2049-2055.

Brown, J.L. (2014) SDMtoolbox: a python-based GIS toolkit for landscape genetic, biogeographic and species distribution model analyses. Methods in Ecology and Evolution, 5, 694-70o.

CGIAR Consortium (2008) SRTM 90 m Digital Elevation Data. Http://srtm.csi.cgiar.org/ [accessed 3 July 2015].

Coutinho (200o) O bioma do Cerrado. In Eugen Warming e o Cerrado Brasileiro: um Século Depois (ed. A.L. Klein), pp. 77-92. UNESP, São Paulo, Brazil.

Cullen, JR, L. (2006) Jaguars as landscape detectives for the conservation of Atlantic forests in Brazil. $\mathrm{PhD}$ thesis. University of Kent, Canterbury, UK.

Cullen, Jr, L., Sana, D.A., Lima, F., De Abreu, K.C. \& Uezu, A. (2013) Selection of habitat by the jaguar, Panthera onca 
(Carnivora: Felidae), in the upper Paraná River, Brazil. Zoologia, 30, 379-387.

De Angelo, C., Paviolo, A. \& Di Bitetti, M. (2011) Differential impact of landscape transformation on pumas (Puma concolor) and jaguars (Panthera onca) in the Upper Paraná Atlantic Forest. Diversity and Distributions, 17, 422-436.

Desbiez, A., Beisiegel, B.M., Campos, C.B., Sana, D.A., Moraes, JR, E.A., Ramalho, E.E. et al. (2013) Plano de Ação Nacional para a Conservação da Onça-Pintada. Instituto Chico Mendes de Conservação da Biodiversidade, Brasília, Brazil.

Doko, T., Fukui, H., Kooiman, A., Toxopeus, A.G., Ichinose, T., Chen, W. \& SKidmore, A.K. (2011) Identifying habitat patches and potential ecological corridors for remnant Asiatic black bear (Ursus thibetanus japonicus) populations in Japan. Ecological Modelling, 222, 748-761.

Elith, J. \& Leathwick, J.R. (2009) Species distribution models: ecological explanation and prediction across space and time. Annual Review of Ecology, Evolution, and Systematics, 40, 677-697.

Ferraz, K.M.P.M.B., Ferraz, S.F.B., De Paula, R.C., Beisiegel, B. \& Breitenmoser, C. (2012) Species distribution modeling for conservation purposes. Natureza \& Conservação, 10, 214-220.

Fischer, J. \& LindenMA Yer, D.B. (2007) Landscape modification and habitat fragmentation: a synthesis. Global Ecology and Biogeography, $16,265-28$.

Fourcade, Y., Engler, J.O., Rödder, D. \& Secondi, J. (2014) Mapping species distributions with Maxent using a geographically biased sample of presence data: a performance assessment of methods for correcting sampling bias. PLOS ONE, 9, e97122.

Grigione, M.M., Menke, K., López-González, C., List, R., Banda, A., Carrera, J. et al. (2009) Identifying potential conservation areas for felids in the USA and Mexico: integrating reliable knowledge across an international border. Oryx, 43, 78-86.

Haag, T., Santos, A.S., Sana, D.A., Morato, R.G., Cullen, Jr, L., Crawshaw, Jr, P.G. et al. (2010) The effect of habitat fragmentation on the genetic structure of a top predator: loss of diversity and high differentiation among remnant populations of Atlantic Forest jaguars (Panthera onca). Molecular Ecology, 19, 4906-4921.

Hatten, J.R., Averill-Murray, A. \& van Pelt, W.E. (2005) A spatial model of potential jaguar habitat in Arizona. Journal of Wildlife Management, 69, 1024-1033.

HydroWe (2010) Bacias Hidrográficas Brasileiras. Http://hidroweb. ana.gov.br/ [accessed 13 December 2014].

ICMBio (Insituto Chico Mendes de Conservação da Biodiversidade) (2014). Brazil Red Book of Threatened Species of Fauna. ICMBIO, Brasília, Brazil.

Lapig (Laboratório de Processamento de Imagens e Geoprocessamento) (2013) Enhanced Vegetation IndexBrazilian Cerrado. Http://www.lapig.iesa.ufg.br/lapig/ [accessed 13 December 2014].

Laporte, I., Muhly, T.B., Pitt, J.A., Alexander, M. \& Musiani, M. (2010) Effects of wolves on elk and cattle behaviors: implications for livestock production and wolf conservation. PLOS ONE, 5 , e11954.

Lehtomäki, J. \& Mollanen, A. (2013) Methods and workflow for spatial conservation prioritization using Zonation. Environmental Modelling \& Software, 47, 128-137.

maA (Ministério do Meio Ambiente) (2015) Resultados da $2^{a}$ Atualização das Áreas Prioritárias para Conservação, Uso Sustentável e Repartição dos Benefícios da Biodiversidade dos Biomas Cerrado, Pantanal e Caatinga. Ministério do Meio Ambiente, Brasília, Brazil.

mma (Ministério do Meio Ambiente) (2016) O bioma Cerrado. Http://www.mma.gov.br/biomas/cerrado [accessed 3 July 2017].
Moilanen, A. (2007) Landscape zonation, benefit functions and target-based planning: unifying reserve selection strategies. Biological Conservation, 134, 571-579.

Moraes, JR, E.A. (2012) The status of the jaguar in the Cerrado. CAT News, Special issue 7, 25-28.

Morato, R.G., Beisiegel, B.D.M., Ramalho, E.E.R., Campos, C.B. \& Boulhosa, R.L.P. (2013) Avaliação do risco de extinção da Onça-pintada (Panthera onca, Linnaeus, 1758) no Brasil. In Avaliação do estado de Conservação dos Carnívoros (eds B. Beisiegel, R. Morato, R. Paula \& R.L. Morato), pp. 122-132. ICMBIO, Brasília, Brazil.

Morato, R.G., Ferraz, K.M.P.M.B., de Paula, R.C. \& Campos, C.B. (2014) Identification of priority conservation areas and potential corridors for jaguars in the Caatinga biome. PLOS ONE, 9, e92950.

Mueller, C.C. \& Martha, JR, G.B. (2008) A agropecuária e o desenvolvimento socioeconômico recente do Cerrado. In Simpósio Nacional Cerrado. Embrapa Cerrados, Brasília, Brazil.

Nepstad, D., Mcgrath, D., Stickler, C., Alencar, A., Azevedo, A., Swette, B. et al. (2014) Slowing Amazon deforestation through public policy and interventions in beef and soy supply chains. Science, 344, 1118-1123.

NijHAWAN, S. (2012) Conservation units, priority areas and dispersal corridors for jaguars in Brazil. CAT News, Special issue 7, 43-47.

Paviolo, A., De Angelo, C., Ferraz, K.M.P.M.B., Morato, R.G., Pardo, J.M., SrbeK-Araujo, A.C. et al. (2016) A biodiversity hotspot without its top predator? The challenge of jaguar conservation in the Atlantic Forest of South America. Scientific Reports, 6, 1-16.

Pearson, R.G. (2010) Species' distribution modeling for conservation educators and practitioners. Lessons in Conservation, 3, 54-89.

Peterson, A.T., Papeş, M. \& Soberón, J. (2008) Rethinking receiver operating characteristic analysis applications in ecological niche modeling. Ecological Modelling, 213, 63-72.

Pettorelli, N., Ryan, S., Mueller, T., Bunnefeld, N., Jedrzejewska, B., Lima, M. \& Kausrud, K. (2011) The normalized difference vegetation index (NDVI): unforeseen successes in animal ecology. Climate Research, 46, 15-27.

Phillips, S., Dudik, M. \& Schapire, R. (2005) Maxent software for species distribution modeling. Https://www.cs.princeton. edu/ schapire/maxent/ [accessed 15 March 2014]

Phillips, S.J., Anderson, R.P. \& Schapire, R.E. (2006) Maximum entropy modeling of species geographic distributions. Ecological Modelling, 190, 231-259.

Qiao, H., Peterson, A.T., Campbell, L.P., Soberón, J., Ji, L. \& Esсов A R, L.E. (2016) NicheA: creating virtual species and ecological niches in multivariate environmental scenarios. Ecography, 39, $805-813$.

Quigley, H., Foster, R., Petracca, L., Payan, E., Salom, R. \& Harmsen, B. (2017) Panthera onca (errata version published in 2018). In The IUCN Red List of Threatened Species 2017: e.T15953A123791436. Http://dx.doi.org/10.2305/IUCN.UK.2017-3. RLTS.T15953A50658693.en [accessed 12 November 2018].

Rabinowitz, A. \& Zeller, K.A. (2010) A range-wide model of landscape connectivity and conservation for the jaguar, Panthera onca. Biological Conservation, 143, 939-945.

REYNOLDS, C. (2012) Brazil's latest agriculture frontier in western Bahia and MATOPIBA. Http://www.pecad.fas.usda.gov/highlights/2012/ 07/Brazil_MATOPIBA/ [accessed 25 April 2015].

Ripple, W.J., Estes, J.A., Beschta, R.L., Wilmers, C.C., Ritchie, E.G., Hebilewhite, M. et al. (2014) Status and ecological effects of the world's largest carnivores. Science, 343, 1241484.

Rodríguez-Soto, C., Monroy-Vilchis, O., Maiorano, L., Boitani, L., Faller, J.C., Briones, M.À. et al. (2011) Predicting 
potential distribution of the jaguar (Panthera onca) in Mexico: identification of priority areas for conservation. Diversity and Distributions, 17, 350-361.

Roques, S., Sollman, R., Jácomo, A., Tôrres, N., Silveira, L., ChÁvez, C. et al. (2016) Effects of habitat deterioration on the population genetics and conservation of the jaguar. Conservation Genetics, 17, 125-139.

Rylands, A.B. \& BRANDON, K. (2005) Brazilian protected areas. Conservation Biology, 19, 612-618.

Sanderson, E.W., Redford, K.H., Chetriewicz, C.-L.B., Medellin, R.A., Rabinowitz, A.R., Robinson, J.G. \& Taber, A.B. (2002) Planning to save a species: the jaguar as a model. Conservation Biology, 16, 58-72.

Sappington, J.M., Longshore, K.M. \& Thompson, D.B. (2007) Quantifying landscape ruggedness for animal habitat analysis: a case study using bighorn sheep in the Mojave Desert. Journal of Wildlife Management, 71, 1419-1426.

SAURA, S. \& Torné, J. (2009) Conefor Sensinode 2.2: A software package for quantifying the importance of habitat patches for landscape connectivity. Environmental Modelling \& Software, 24, 135-139.

Sollmann, R., Furtado, M.M., Gardner, B., Hofer, H., Jácomo, A.T.A., Tôrres, N.M. \& Silveira, L. (2011) Improving density estimates for elusive carnivores: accounting for sex-specific detection and movements using spatial capture-recapture models for jaguars in central Brazil. Biological Conservation, 144, 1017-1024.
Strassburg, B.B.N., Brooks, T., Feltran-Barbieri, R., Iribarrem, A., Crouzeilles, R., Loyola, R. et al. (2017) Moment of truth for the Cerrado hotspot. Nature Ecology \& Evolution, 1, 0099 .

Taylor, P., Fahrig, L., Henein, K. \& Merriam, G. (1993) Connectivity is a vital element of landscape structure. Oikos, $68,571-573$.

UNDP (United National Development Programme) (2018) Human Development Index. Http://hdr.undp.org/en/ content/human-development-index-hdi [accessed 28 November 2018].

Vynne, C., Keim, J.L., Machado, R.B., Marinho-Filho, J., Silveira, L., Groom, M.J. \& Wasser, S.K. (2011) Resource selection and its implications for wide-ranging mammals of the Brazilian cerrado. PLOS ONE, 6, e28939.

Warren, D. \& Seifert, S.N. (2011) Ecological niche modeling in Maxent: the importance of model complexity and the performance of model selection criteria. Ecological Applications, 21, 335-342.

Woods Hole Research Center (2007) Detailed vegetation height estimates across the tropics. Http://whrc.org/publications-data/ datasets/detailed-vegetation-height-estimates-across-the-tropics/ [accessed 8 December 2015].

Zeller, K. (2007) Jaguars in the New Millennium Data Set Update: the State of the Jaguar in 2006. Wildlife Conservation Society, Takoma Park, Washington DC, USA. 